\title{
MIXED FUZZY-LOGIC AND GAME-THEORETICAL APPR0ACH TO JUSTIFY VEHICLE MODELS FOR SERVICING THE PUBLIC BUS LINE
}

\author{
Vitalii Naumov ${ }^{1, *}$, Laura Bekmagambetova ${ }^{2}$, Zukhra Bitileuova², Zhumazhan Zhanbirov³, Igor Taran ${ }^{4}$ \\ ${ }^{1}$ Faculty of Civil Engineering, Cracow University of Technology, Cracow, Poland \\ ${ }^{2}$ Faculty of Logistics and Transport Management, Kazakh Academy of Transport and Communications, Almaty, \\ Kazakhstan \\ ${ }^{3}$ Faculty of Fundamental Sciences, Central-Asian University, Almaty, Kazakhstan \\ ${ }^{4}$ Department of Transport Management, Dnipro University of Technology, Dnipro, Ukraine \\ *E-mail of corresponding author: vnaumov@pk.edu.pl
}

\section{Resume}

One of the main problems to be solved by the transport operators is the substantiation of the vehicle models servicing the transport lines. A gametheoretical approach is proposed in this paper to justify the bus model choice based on the passengers' preferences and the structure of the passenger flows. To estimate the customers' preferences, the membership functions for fuzzy sets of the optimal vehicle models were defined. The simulation experiment aiming to estimate the city fleet structure in terms of the vehicles' capacity was conducted for the Talas city (Kazakhstan) based on the proposed approach with use of the corresponding software implementation of the developed mathematical models. As a result of the experimental studies, the impact of the passengers' flow structure and the number of carriers on the rational structure of the city bus fleet was studied in the paper.

\section{Article info}

Received 17 April 2021

Accepted 9 July 2021

Online 4 November 2021

\section{Keywords:}

public transport, game theory, fuzzy logic, fleet optimization

ISSN 1335-4205 (print version) ISSN 2585-7878 (online version)

\section{Introduction}

Contemporary markets of the public transport services in the cities are highly stochastic environments where several servicing transport companies compete for the preferences of clients - the passengers who use the public transport lines.

The carrier's goal within the public transport system is the most complete coverage of the existing and potential market, for which it is necessary to attract passengers moving from and to the points that the transport line covers. If the fulfillment of the passenger's need for travel is possible in one way only - by using a single bus line available, then the carrier gets the maximum possible share of the market sector. However, if the need for movement can be realized in more than one way (the trip can be implemented by the means of more than one public transport line), the passenger has a choice. In that case, there will be a conflict situation between carriers who can potentially serve the same trip. Depending on the strategy chosen by the carrier, the passenger will give preference to the corresponding bus line.

This study aims to determine the optimal quality composition of the city bus fleet, considering the interests of passengers and carriers. The main objective of this research is to determine the optimal carrier strategy (in terms of the choice of bus models) that guarantees the biggest possible market share.

\section{Literature review}

Buses are the most popular elements of public transport. Nowadays improvement of the passenger market takes place in main directions: promoting sustainable mobility solutions and usage of e-transport; timetabling and vehicle scheduling; solving vehicle routine problems; fleet size and fleet mix optimization.

The problem of choosing the optimal bus models for servicing the existing route network of a city, considering the specific preferences of passengers and existence of competing routes, is particularly relevant. Many publications have arisen recently that propose different approaches to solve that problem.

The simulation-based approach to justify the number of vehicles at the public bus routes in cities is proposed in [1]. The authors of research [2] provide a methodology to solve the problem of cost-optimized planning for the fleet of electric buses, whereas the study [3] presents a fleet replacement problem that allows 
determining the bus replacement plans by considering total costs.

Various optimization techniques are used by researchers to solve the fleet optimization problem. The paper [4] provides a proper decision-making procedure regarding the process of replacing a diesel fleet with alternative-technology buses by using a deterministic mixed-integer programming model. The study [5] develops a framework to investigate the bus fleet operation risks by using probabilistic simulations. In the research [6], the problem of dispatching time control in rolling horizons is modeled, following a periodic optimization approach.

Timetabling and vehicle scheduling are the basis of security and efficiency for various bus enterprises. The paper [7] presents a model to optimize the bus schedule by considering bus stops and route segments as the integrated structure. The dynamic scheduling procedures that allow adapting timetables to demand and traffic conditions are considered by the authors of the study [8], as well. The article [9] deals with the flexible vehicle and crew scheduling problem to assign available resources to cover generated timetables. The study [10] also solves the bus and driver scheduling problems with mealtime windows for a single public transport bus route by using a self-adaptive search method. The authors of paper [11] propose an optimization model for designing the intervals and capacity of buses by minimizing the system's operating costs and users' personal costs.

The vehicle routing problem is about finding optimal routes for a fixed fleet of vehicles so that they can meet the demands of a set of given customers by traveling through those paths. This problem and its numerous expansions are one of the most important and most applicable transportation and city logistics problems [12]. Urban public transport operations in the peak periods, characterized by highly uneven demand distributions and scarcity of resources, are considered in the article [13]: the authors simultaneously reduce passenger waiting times and transport operational costs. Similar efficiency criteria are used by the author of the research [14] for solving the timetables synchronization problem at the public transport lines, whereas the authors of the paper [15] consider improvement of the passenger transportation process at the expense of the combined operating mode.

The next group of studies combines problems of routing, optimal vehicle-mix, fleet selection and transport demand within the city territory. The research [16] develops a framework to maximize service performance in a set of high-frequency bus routes, given their planned headways and a total fleet size constraint. The authors of the paper [17] introduce a fleet size and a mix dial-a-ride problem with multiple passenger types and a heterogeneous fleet. The study [18] introduces the solution to a strategic problem of fleet renewal to meet the future operational needs under uncertain conditions. The authors of the research [19] aim to solve the fleet size and mix location-routing problem by considering a heterogeneous fleet and time windows. The paper [20] describes a probabilistic formulation that provides the global optimum selection and allocation of a bus fleet in the case when a third party is involved in transportation. The authors of the research [21] present a mathematical model aiming to minimize the total costs for the passengers and the transport operator by substantiating the number of buses and the dynamic holding time.

The completed review of the contemporary literature on the research topic shows that despite considering by the authors of numerous cases and efficiency criteria, there are no approaches that consider the competitive nature of the market of public transport services. In this paper, authors aimed to fill this gap by developing the game-theoretical approach to substantiate the carriers' strategies in terms of the bus fleet management.

\section{Approach to substantiate the bus models for servicing passengers at public transport lines}

The $K$ origin-destination pairs (O-D pairs) that are served by $n$ public transport lines are considered, assuming that any combination of $m$ bus models can be chosen for passengers' servicing.

It is assumed that one line is served by one carrier. If one carrier serves several lines or one line is served by several carriers, the tuple "carrier-line" can be selected as a unit and further, be considered in the model as one carrier (one public transport line).

Let the vector $Q$ be the total number of trips per O-D pair within the line, while the number of elements of the vector $Q$ is equal to $K$ :

$Q=\left\{q_{1}, q_{2}, \ldots, q_{K}\right\}$

where: $q_{j}$ is the number of completed trips per $j$-th O-D pair [pax].

The matrix $\Omega$ for assigning the transport lines to O-D pairs is defined with elements of the matrix being $\omega_{i j}=1$ if the $i$-th carrier can serve the $j$-th O-D pair (can satisfy the passengers need to travel from one city district to another - the bus line includes these stops in corresponding city districts) and the matrix elements are equal to 0 in otherwise. Then the sum of the elements of this matrix along the $j$-th column will show the number of competitive lines potentially serving the $j$-th O-D pair and the sum of the elements along the $i$-th row $\sum_{j=1}^{K} \omega_{i j}$ - the number of O-D pairs that can potentially be served by $i$-th public transport line.

If $\omega_{i j}=1$, then the $j$-th O-D pair is potentially served by the $i$-th carrier, however, if the used bus models or other conditions of the servicing process do not satisfy the passengers for the given O-D pair, they can refuse in whole or in part from the services of this 
bus line (if there is an alternative available). The matrix $\Delta$ is defined, the elements of which $\delta_{i j}$ determine the share that the $i$-th carrier takes when servicing the $j$-th O-D pair. It's obvious that $\delta_{i j}=0$ if $\omega_{i j}=0$ and $\delta_{i j} \in[0,1]$ if $\omega_{i j}=1$.

If the number of trips per each O-D pair $\mathbf{Q}$ and the distribution of trips between carriers $\Delta$ are known, then the vector $\mathbf{P}$ of passenger traffic values on public transport lines is determined as follows:

$$
\mathbf{P}=\Delta \cdot \mathbf{Q}^{\mathrm{T}}
$$

In this case, values of elements for the vector $\mathbf{P}$ can be calculated as

$$
p_{i}=\sum_{j=1}^{K} \delta_{i j} \cdot q_{j}
$$

Given the values of $p_{i}$, it is possible to determine the required number of buses to operate on the lines and hence - the quantitative composition of the city bus fleet. Thus, the solution to the problem of determining the quantitative composition of the fleet can be obtained if the matrix $\Delta$ and the number of trips per O-D pair are known. However, the assignment of trips to public transport lines depends on preferences of passengers and the importance of the given O-D pair for a carrier (meaning that the carrier determines the strategy of behavior depending on the attractiveness of a particular O-D pair).

Passenger preferences, when choosing a public transport line, depend on three main indicators: delivery speed (travel time), comfort and service price. All of the above parameters are, to one degree or another, determined by the bus model. The delivery speed depends on the design features (however, in addition, the traffic speed is affected by the congestion of the road network and the used methods of traffic management). Comfortability directly depends on the passenger capacity of a vehicle and the design features of the cabin and suspension. The price of the service is determined based on the costs of the service, which depend on the performance characteristics of a particular bus model. Thus, one can say that the preferences of passengers when choosing a particular bus line depend on the bus models used by the given carrier. This assumption does not consider the timetables of public transport lines: that feature could be provided in the assessment of the passengers' preferences if the passengers' opinion on the service frequency would be studied (this characteristic was not covered in this study).

It is convenient to describe the preference by passengers of a particular bus model through a fuzzy subset of the given bus model belonging to the set of optimal models. In this case, the preference for different O-D pairs or for a given O-D pair at different times of the day (day of the week) will be different. So, for the O-D pairs associated with a sleeping area in the city, the significance of the delivery speed is different depending on the time of day. In general, each O-D pair can be divided into subgroups of transport service consumers, based on the purpose of the trip, while the composition of O-D pairs will determine the type of the membership function.

If the preference by the criterion of the travel speed is described by the membership function $\mu_{v}$, by the criterion of comfort - by the function $\mu_{K}$ and by the criterion of price - by the function $\mu_{T}$, with $\mu_{v} \in[0 ; 1], \mu_{K} \in[0 ; 1]$ and $\mu_{T} \in[0 ; 1]$, then the passenger's general preference can be expressed through a fuzzy subset $\mu$, which is a combination of the subsets $\mu_{v}, \mu_{K}$ and $\mu_{T}$, as:

$\mu=f\left(\mu_{v}, \mu_{K}, \mu_{T}\right)$.

The importance $v_{i j}$ of the $j$-th O-D pair for the $i$-th carrier is determined based on the specific weight of the number of trips performed for the given O-D pair in the potential passenger traffic on the line (the bigger the number of trips for the O-D pair, the more attractive it is for the carrier):

$v_{i j}=\frac{q_{j}}{\sum_{j=1}^{K} \omega_{i j} \cdot q_{j}}$,

where: $\sum_{j=1}^{K} \omega_{i j} \cdot q_{j}$ is the maximum possible (potential) passenger traffic on a bus line (the passenger traffic that will be served by the line, if for all the covered O-D pairs $\left.\delta_{i j}=\omega_{i j}=1\right)$ [pax].

A conflict situation between $n_{j}$ carriers serving the $j$-th O-D pair is considered as a game of $n_{j}$ persons [22]. Each of the carriers has at most $m$ alternatives (bus models). Moreover, if the $i$-th carrier chooses the $k$-th model $\left(k_{i}=1,2, \ldots, m\right)$ and the $(i+1)$-th carrier chooses the same or another $k_{i+1}$-th model of the vehicle, then each of them, as a result, will win a certain share of trips for the $j$-th O-D pair. Or, using the terminology of the game theory, one can say that when choosing the $k_{i}$-th option, the $i$-th player's payoff will be the share $\delta_{i j}$ of trips for the $j$-th O-D pair.

Obviously, the ratio of the number of passengers who choose the $i$-th carrier to the number of passengers who choose the $(i+1)$-th carrier is equal to the ratio of the trips share for the $i$-th carrier to the trips share for the $(i+1)$-th carrier. In this case, the part of trips $\delta_{i j}$ is directly proportional to the importance for the $i$-th carrier of the $j$-th O-D pair and the preference by passengers from the $j$-th O-D pair of the $k$-th bus model:

$\frac{\delta_{i j}}{\delta_{(i+1) j}}=\frac{v_{i j} \cdot \mu_{j k_{i}}}{v_{(i+1) j} \cdot \mu_{j k i+1}}$.

On the other hand, if one proceeds from the condition that the passengers' demand for travel is fully satisfied by carriers, then

$\sum_{i=1}^{n j} \delta_{i j}=1$. 
Thus, to determine the payoffs of each of the $n$ players, it is necessary to solve the system of Equations (6) and (7). It is easy to show that this system has the following solution:

$$
\delta_{i j}=\frac{v_{i j} \cdot \mu_{j k i}}{\sum_{i=1}^{n j} v_{i j} \cdot \mu_{j k i}} .
$$

Knowing the payoffs of each of the players, it is possible to solve the described game and the solution will be the optimal strategies of each of the players (optimal bus models). The set of solutions will determine the optimal qualitative structure of the city bus fleet.

\section{Game-theoretical approach to choose carriers' strategies at the market of public transport services}

According to definition of the game [22], a conflict situation between $n_{j}$ carriers serving the $j$-th O-D pair can be formally represented in the following way:

$$
\Gamma=\left\langle R_{D},\left\{r_{\kappa}\right\}_{\kappa \in R_{D}}, r, R_{I},\left\{R_{\kappa}\right\}_{\kappa \in R_{I}}\right\rangle,
$$

where: $R_{D}$ is the set of all the decision-making parties; $R_{I}$ is the set of all the subjects defending certain interests,

$r_{\kappa}$ is the set of all the admissible decisions (strategies) of the game participants who make the decision; $r$ is the set of all the situations (outcomes) of the game;

$R_{\kappa}$ is the set of all interests of the parties concerned in the conflict.

Moreover, the set $r$ is a subset of the Cartesian product for the sets of all the strategies of the participants involved in the game $r$ :

$$
r=\prod_{\kappa \in R_{D}} r_{\kappa}
$$

and the set of all interests $R_{\kappa}$ is a binary relation on the set $r$ :

$$
R_{\kappa} \subset r \times r, \kappa \in R_{I} .
$$

In accordance with the definition of the game in Equation (9), the set of all the decision-making subjects is the set of carriers (public transport lines). The carrierline pair is a member of the $R_{D}$ set. In the case when one carrier serves several lines, the set of elements of the set $R_{D}$ for this carrier form a coalition.

The $R_{I}$ set (the set of coalitions of interests) contains subsets such as carriers and passengers; city administrations can also be considered as an element of this set with further consideration of the influence of this element on the outcome of the game, however, in this study, when modeling a conflict situation $r$, such a participant is not taken into account.
The elements of the set $r_{\kappa}$ are possible strategies of carriers with respect to the qualitative (in terms of the model range) and quantitative composition of the bus fleet. It is convenient to represent an element of the set of all the admissible strategies in the form of a vector $\Phi \subset r_{\kappa}$ :

$\Phi=\begin{array}{cccc}\alpha_{1} & \alpha_{2} & \ldots & \alpha_{m} \\ \mid \varphi_{1} & \varphi_{2} & \ldots & \varphi_{m}\end{array} \mid$

where: $\alpha_{1}, \alpha_{2}, \ldots, \alpha_{m}$ are the alternative bus models; $\varphi_{1}, \varphi_{2}, \ldots, \varphi_{m}$ are the probabilities of using the corresponding bus models, $\sum_{k=1}^{m} \varphi_{k}=1$.

In this case, the carrier's strategy is pure if one model of the bus $\alpha_{k^{*}}$ is used for operation on the route, i.e. $\varphi_{k^{*}}=1$ and $\varphi_{k\left(k \neq k^{*}\right)}=0$ for $k=1,2, \ldots, m$. The carrier's strategy is mixed otherwise (several different bus models are used to work on the line when serving the given O-D pair), while the number of buses of the $k$-th model should be proportional to $\varphi_{k}$.

The set of all the outcomes of the game is presented by vectors, which elements $\delta_{i j}$ are values, for each $i$-th carrier for the considered $j$-th O-D pair. As elements of the set of interests $R_{\kappa}$ of interested parties (passengers and carriers), we will consider the most complete coverage of target market segments (O-D pairs), considering the number of trips per O-D pair - for transport companies and the highest satisfaction of the existing needs for travel - for passengers.

Next, the following alternatives are considered, which arise when choosing the most rational bus models when servicing a given O-D pair:

- trips for the O-D pair can potentially be served by only one carrier;

- trips for the O-D pair can potentially be served by two carriers;

- trips for the O-D pair can potentially be served by more than two carriers.

Obviously, for the first option, the carrier needs to apply a pure strategy and choose the bus model for servicing the O-D pair trips that most satisfies the passengers:

$\left[\varphi_{k^{*}}=1, \varphi_{k\left(k \neq k^{*}\right)}=0\right.$,

$k^{*}=\operatorname{argmax} \mu_{j k}$.

In the second version, the game $r$ will be a game of two persons $-\Psi_{1}$ and $\Psi_{2}$. Let's define the payment matrix for this variant of the game. If one assumes that each of the players has the same opportunities when choosing the vehicle models, then the payment matrix will be of size $m \times m$, where $m$ is the number of alternative bus models. When some strategy is chosen by the player $\Psi$, the share of trips for the considered O-D pair is $\delta_{\Psi_{1}}$, when a strategy is chosen by the player $\Psi_{2}$, his share is $\delta_{\Psi_{2}}$, where $\delta_{\Psi_{1}}$ and $\delta_{\Psi_{2}}$ are calculated according to Equation (8). The payment matrix for this game is defined as: 


$$
\Delta^{*}=\begin{array}{c|cccc}
\alpha_{1} & \alpha_{2} & \ldots & \alpha_{m} \\
\alpha_{1} & \delta_{11}^{*} & \delta_{121}^{*} & \ldots & \delta_{1 m}^{*} \\
\alpha_{2} & \delta_{21}^{*} & \delta_{22}^{*} & \ldots & \delta_{2 m 1}^{*} \\
\ldots & \ldots & \ldots & \ldots & \ldots \\
\alpha_{m} & \delta_{m 1}^{*} & \delta_{m 1}^{*} & \ldots & \delta_{m m}^{*}
\end{array} \mid
$$

where: $\delta^{*}=\delta_{\Psi_{1}}+\delta_{\Psi_{2}}$.

Based on the assumption that the needs of passengers in travels are fully satisfied, one can say that

$$
\delta_{\Psi 1}+\delta_{\Psi 2}=1
$$

Then the element of the payoff matrix can be defined in the following way:

$$
\delta^{*}=2 \cdot \delta_{\Psi_{1}}-1
$$

Since according to the definition of the game in Equation (9), the element of the set of interests $R_{\kappa}$ is the most complete coverage of the O-D pair trips, one can say that the task for the player $\Psi_{1}$ is to win the biggest possible share of trips for the j-th O-D pair. From Equation (16) these conditions are satisfied when the value of $\delta^{*}$ is reached (the more $\delta^{*}$, the bigger is the $\delta_{\Psi_{1}}$ value). The task for the player $\Psi_{2}$ is similar and the condition for a set of interests will be satisfied if the payoff of the player $\Psi_{1}$ is the smallest possible value.

One can see that, for the second variant in the

above setting, the game $\mathbf{\Gamma} \boldsymbol{\Gamma}$ takes the form of a matrix game with zero-sum. When solving such a game, the principle of obtaining the maximum guaranteed result under the worst conditions is used: the player $\Psi_{1}$ seeks to adopt a strategy that should ensure the maximum loss of the player $\Psi_{2}$. Accordingly, the player $\Psi_{2}$ seeks to adopt a strategy that ensures the minimum payoff of the player $\Psi_{1}$ (as mentioned above, such a strategy will ensure the maximum payoff of the player $\Psi_{2}$ ). According to [22], if the lower value of the pure game price (maximin) matches the upper value of the pure game price (minimax), i.e.

$$
\max _{k \Psi_{1}} \min _{k \Psi_{2}} \delta_{k \Psi_{1} k \Psi_{2}}^{*}=\min _{k \Psi_{2}} \max _{k \Psi_{1}} \delta_{k \Psi_{1} k \Psi_{2}}^{*},
$$

then the solution of such a game will be the pure optimal strategies $\alpha_{k \Psi_{1}}$ and $\alpha_{k_{2}}$ of the players $\Psi_{1}$ and $\Psi_{2}$ (in this case, the game $\Gamma$ has a saddle point).

If the game $\Gamma$ does not have a saddle point (that is, condition in Equation (17) is not satisfied), then the strategies of the players will be mixed: mixed strategies are applied if the game does not have a saddle point, the game is repeated many times under similar conditions and averaging of the game results allows the solution estimation. In this case, the solution of the game is found by the main theorem for arbitrary rectangular games [22], according to which every matrix game has a solution and a player in such a game always has an optimal strategy. The price of the game in this case is determined as follows:

$$
\delta_{o p t}^{*}=\max _{\Phi_{1}} \min _{\Phi_{2}} \sum_{k \Psi_{1}=1}^{m} \sum_{k \Psi_{2}=1}^{m} \varphi_{k \Psi_{1}} \varphi_{k \Psi_{2}} \delta_{k \Psi_{1} k \Psi_{2} 2}^{*},
$$

where: $\Phi_{1}$ and $\Phi_{2}$ are the strategies of the players $\Psi_{1}$ and $\Psi_{2}$ correspondingly.

The problem of finding the optimal strategies $\Phi_{1}$ and $\Phi_{2}$ can be solved by sequentially enumerating the probabilities $\Phi_{1}, \Phi_{2}, \ldots, \Phi_{m}$ of choosing the bus models $\alpha_{1}, \alpha_{2}, \ldots, \alpha_{m}$ with the given step $s, s \in(0,1]$, whereby the optimality criterion is the condition in Equation (18). In this case, the total number of enumerations $N_{v}$ may be estimated as

$N_{v} \approx s^{-2 \cdot m}$.

Since in practice more than $3-4$ bus models are rarely used on one city transport line, the number of enumerations with the step of $10^{-1}$ will be about $10^{6} \div 10^{8}$ per O-D pair, which is implementable by using contemporary computers in a reasonable time.

If the $j$-th O-D pair can be potentially served by more than two carriers, then the pairwise games of each of the players against the coalition of the remaining competitors should be considered to determine the optimal strategies. In this case, the $i$-th carrier is the player $\Psi_{1}$ and the player $\Psi_{2}$ is the coalition of the remaining transport companies potentially serving the given O-D pair. The element of the payment matrix for such a game is determined similarly by dependence in Equation (16).

As a result of solving a set of conflict situations for all the considered O-D pairs, optimal strategies $\Phi_{i j}$ of each of the competing transport companies can be obtained for the set of O-D pairs served by the $i$-th carrier:

$\Phi_{i}^{*}=\left|\begin{array}{cccc}\varphi_{11} & \varphi_{12} & \ldots & \varphi_{1 m} \\ \varphi_{21} & \varphi_{22} & \ldots & \varphi_{2 m} \\ \ldots & \ldots & \ldots & \ldots \\ \varphi_{K 1} & \varphi_{K 1} & \ldots & \varphi_{K m}\end{array}\right|$,

where: $\Phi_{i}^{*}$ is the matrix containing the set of optimal strategies of the $i$-th transport company.

It should be noted that if the $i$-th carrier cannot potentially serve the $j$-th O-D pair, then all the elements of the corresponding row of the matrix $\Phi_{j}^{*}$ are equal to 0 .

Based on particular optimal strategies for the $j$-th O-D pair, the optimal qualitative structure of the bus fleet of the $i$-th carrier is defined as follows:

$d_{i k}=\frac{\sum_{j=1}^{K} \varphi_{j k}}{\sum_{j=1}^{K} \omega_{i j}}$,

where: $d_{i k}$ is the part of vehicles of the $k$-th model at the $i$-th public transport line. 


\section{Case study and discussion}

To calculate the optimal structure of the city's bus fleet using the developed models, it is necessary to determine the type of membership functions for a fuzzy subset of optimal bus models and standardize them for the main categories of passengers.

To define the dependencies for estimation of the membership functions, the methodology for analyzing the results of an expert survey was used. The passenger preference survey was conducted in October 2019 in the city of Talas (Kazakhstan). Within the survey, the preferences of the following social groups were identified: adults of working age, students and retirees. The survey was conducted at the bus stops of the Talas public transport system. First, the respondents answered the group of questions related to their social status (age, source of income, the average income, etc.). Afterwards, the respondents were asked to assess their preference related to the transport line choice for three basic features: the level of tariff, comfortability and travel speed. The detailed survey results are discussed in [23].

Based on the results of the conducted survey, the regression models for the membership functions were defined as the third-degree polynomial models. The results of calculating the coefficients of polynomial models to determine the dependence of the preference function on the value of the corresponding features are presented in [23].

The obtained polynomial models are used to determine e values of the function in Equation (4). The resulting membership function can be estimated as the weighted average for the partial membership functions:

$\mu=a_{v} \cdot \mu_{v}+a_{K} \cdot \mu_{K}+a_{T} \cdot \mu_{T}$,

where: $a_{v}, a_{K}, a_{T}$ are the weighting factors for preference functions according to travel speed, comfort and tariff, respectively.

The weighting coefficients were evaluated as the arithmetic mean values for all the respondents participated in the survey: $a_{v}=0.321, a_{K}=0.322$, $a_{T}=0.357$. As we can see, the selected features are evaluated by passengers in almost the same way.

The mathematical model for estimation of the transport companies' strategies related to the vehicle fleet was implemented in Python programming language. A detailed description of the basic software framework can be found presented in [24]. The developed software was used as the simulation tool to assess the bus fleet structure for all the transport companies servicing the public transport system of the Talas city (in total, 13 carriers are involved in the process of servicing 53 bus lines in the city).

To represent the structure of the city's bus fleet in the aggregated form, 4 groups of vehicles are distinguished according to the vehicles' capacity (up to 16 pax., from
17 to 24 pax., from 25 to 40 pax. and more than 40 pax.). Thus, the aggregated structure of the city bus fleet can be shown as a vector $D$ :

$$
D=\left|\begin{array}{llll}
d_{1} & d_{2} & d_{3} & d_{4}
\end{array}\right|,
$$

where: $d_{i}$ is the share of buses of the $i$-th group.

It should be mentioned that the proposed model does not consider the fleet structure in terms of the age of vehicles, the type of fuel, etc. The capacity is distinguished as the main feature influencing the passengers' preferences.

Influence of characteristics of the existing public transport network on the optimal structure of the city bus fleet is now determined. For that purpose, the regression models are constructed of dependence of the buses' share on the structure of the passengers' flows and the number of carriers servicing the public transport lines. The following explanatory variables are considered in the regression models:

- share $\varepsilon_{a}$ of adult passengers of working age;

- share $\varepsilon_{S}$ of students;

- share $\varepsilon_{r}$ of retirees;

- the number $n$ of carriers.

The number of trips performed per each O-D pair is a highly stochastic variable since it is influenced by many factors that are difficult to enumerate and predict. Therefore, as a random factor characterized by the external environment, are considered: the number of O-D pairs, the place of their origin and destination (respectively, the possibility of servicing by a specific bus line) and the number of trips per O-D pair. Then, according to the proposed model for determining the optimal structure of the bus fleet, the total number of O-D pairs $K$, the vector representing the number of trips $Q$ and the matrix of assigning O-D pairs to bus lines $\Omega$ will be random.

For the listed explanatory variables, the full-factor simulation experiment was conducted: the number of competing transport companies was considered in the range from 2 to 20 , the shares of passengers were considered in the range from 0 to 1 assuming that the sum of shares for all the passenger groups is equal to 1 . The number of model's runs in each of the experiment series was 300 that guarantees the probability of confidence in $95 \%$ for the obtained results.

To assess the influence of input factors on the system output (the structure of the city bus fleet), the linear functional dependence was used for the regression models:

$d_{i}=b_{0 i}+b_{1 i} \cdot \varepsilon_{a}+b_{2 i} \cdot \varepsilon_{s}+b_{3 i} \cdot \varepsilon_{r}+b_{4 i} \cdot n$,

where $b_{j i}$ are the regression coefficients, $i=1 \ldots 4$.

As a result of the regression analysis based on the conducted simulation experiment, the following linear models were obtained: 
Table 1 Change in the rational structure of the city bus fleet with a $10 \%$ increase in indicators [\%]

\begin{tabular}{lcccc}
\hline Indicator & \multicolumn{5}{c}{ Group of buses } \\
& 1 & 2 & 3 & 3.03 \\
\hline part of adults & 4.72 & 3.18 & 3.56 & 3.15 \\
part of students & 1.42 & 2.67 & 3.08 & 3.11 \\
part of retirees & 3.48 & 3.82 & -1.35 & 1.34 \\
number of bus lines & -2.97 & -2.38 & & \\
\hline
\end{tabular}

$\left[\begin{array}{l}d_{1}=0.10 \cdot \varepsilon_{a}+0.03 \cdot \varepsilon_{s}+0.07 \cdot \varepsilon_{r}+1.0 \cdot 10^{-7} \cdot n \\ d_{2}=0.14 \cdot \varepsilon_{a}+0.11 \cdot \varepsilon_{s}+0.16 \cdot \varepsilon_{r}+9.3 \cdot 10^{-9} \cdot n \\ d_{3}=0.23 \cdot \varepsilon_{a}+0.27 \cdot \varepsilon_{s}+0.23 \cdot \varepsilon_{r}+5.0 \cdot 10^{-8} \cdot n \\ d_{4}=0.54 \cdot \varepsilon_{a}+0.59 \cdot \varepsilon_{s}+0.53 \cdot \varepsilon_{r}+4.3 \cdot 10^{-8} \cdot n\end{array}\right.$

Note that free coefficients $b_{0 i}$ are taken as zero values for the developed regression models (for such values, the adequacy of the models rises significantly). The obtained regression models are characterized by high adequacy: the determination coefficient is higher than 0.9 for each of the presented models. All the coefficients in the regression models in Equation (25) are statistically significant for the significance level of 0.05 .

The next investigated is the influence of parameters on the required share of buses for all the possible options for the rational structure of the vehicle fleet. To do this, the change in the share of buses of each group was calculated, with a $10 \%$ increase in the parameters that determine the structure of the bus fleet. The increase in the share of buses $\Delta d_{j}$ for the variant of the bus fleet structure for the $j$-th group is calculated by the formula

$\Delta d_{j}=\frac{d_{j}(\bar{x}+\Delta x)}{d_{j}(\bar{x})} \cdot 100 \%$,

where $\bar{x}$ is the average value of the indicator;

$\Delta x$ is the indicator's increment, $\Delta x=0.1 \cdot \bar{x}$.

The results of estimating the change in the share of buses with a $10 \%$ increase in the parameters that determine the structure of the city bus fleet are shown in Table 1.

According to Table 1, it can be noted that the change in the structure of transport service consumers has the greatest impact on the structure of the bus fleet. Moreover, an increase in the proportion of the workingage adult passengers leads to the greatest increase in the optimal proportion of buses with especially low passenger capacity characterized by the highest tariff and the highest delivery speed. With an increase in the share of passengers of retirement age, the biggest increase is in the share of buses with an average passenger capacity and with an increase in the share of students, the optimal share of buses with a large passenger capacity grows.

With an increase in the number of routes, the share of buses in each of the first three groups decreases and the share of buses with a particularly large passenger capacity increases. This trend is positive in terms of reducing the traffic congestion and decreasing the environmental pollution by reducing the total number of buses.

\section{Conclusions}

The developed approach to determining the optimal qualitative and on its basis - the quantitative structure of the city bus fleet allows considering the preferences of consumers of transport services and the competitive nature of the transportation market. The use of the proposed method in practice allows transport engineers to assess the model range of the city's bus fleet.

The proposed methodology makes it possible to determine the optimal models of buses for transporting passengers and a rational quantitative ratio of buses of these models for each of the carriers for a city's existing public transport network. An obvious inconvenience of using this technique is the cumbersomeness of the calculations, which can be eliminated by creating a specialized software.

Analysis of influence of determining factors on the structure of the bus fleet allows to conclude that the change in the composition of consumers of transport services has the biggest impact on the fleet structure.

As the future research direction, it is planned to perform the studies with use of the developed approach based on other locations to confirm the obtained membership functions and the discovered influence of the passenger flows structure on the structure of the city bus fleet.

\section{References}

[1] NAUMOV, V. Optimizing the number of vehicles for a public bus line on the grounds of computer simulations. In: 5th IEEE International Conference on Models and Technologies for Intelligent Transportation Systems 2017: proceedings [online]. 2017. ISBN 978-1-5090-6484-7, p. 176-181. Available from: https://doi.org/10.1109/ MTITS.2017.8005661 
[2] ROGGE, M., VAN DER HURK, E., LARSEN, A., SAUER, D. U. Electric bus fleet size and mix problem with optimization of charging infrastructure. Applied Energy [online]. 2018, 211, p. 282-295. ISSN 0306-2619. Available from: https://doi.org/10.1016/j.apenergy.2017.11.051

[3] PELlETIER, S., JABALI, O., MENDOZA, J. E., LAPORTE, G. The electric bus fleet transition problem. Transportation Research Part C: Emerging Technologies [online]. 2019, 109, p. 174-193. ISSN 0968-090X. Available from: https://doi.org/10.1016/j.trc.2019.10.012

[4] ISLAM, A., LOWNES, N. When to go electric? A parallel bus fleet replacement study. Transportation Research Part D: Transport and Environment [online]. 2019, 72, p. 299-311. ISSN 1361-9209. Available from: https://doi.org/10.1016/j.trd.2019.05.007

[5] HARRIS, A., SOBAN, D., SMYTH, B. M., BEST, R. A probabilistic fleet analysis for energy consumption, life cycle cost and greenhouse gas emissions modelling of bus technologies. Applied Energy [online]. 2020, 261, 114422. ISSN 0306-2619. Available from: https://doi.org/10.1016/j.apenergy.2019.114422

[6] GKIOTSALITIS, K. A model for the periodic optimization of bus dispatching times. Applied Mathematical Modelling [online]. 2020, 82, p. 785-801. ISSN 0307-904X. Available from: https://doi.org/10.1016/j. apm.2020.02.003

[7] WAGAlE, M., SINGH, A. P., SARKAR, A. K., ARKATKAR, S. Real-time optimal bus scheduling for a city using a DTR model. Procedia - Social and Behavioral Sciences [online]. 2013, 104, p. 845-854. ISSN 1877-0428. Available from: https://doi.org/10.1016/j.sbspro.2013.11.179

[8] KUMAR, B. A., PRASATH, G. H., VANAJAKSHI, L. Dynamic bus scheduling based on real-time demand and travel time. International Journal of Civil Engineering [online]. 2019, 17, p. 1481-1489. ISSN 2383-3874. Available from: https://doi.org/10.1007/s40999-019-00445-y

[9] BOYER, V., IBARRA-ROJAS, O.J., RIOS-SOLIS, Y. A. Vehicle and crew scheduling for flexible bus transportation systems. Transportation Research Part B: Methodological [online]. 2018, 112, p. 216-229. ISSN 0191-2615. Available from: https://doi.org/10.1016/j.trb.2018.04.008

[10] KANG, L., CHEN, S., MENG, Q. Bus and driver scheduling with mealtime windows for a single public bus route. Transportation Research Part C: Emerging Technologies [online]. 2019, 101, p. 145-160. ISSN 0968-090X. Available from: https://doi.org/10.1016/j.trc.2019.02.005

[11] IBEAS, A., ALONSO, B., DELL'OLIO, L., MOURA, J. L. Bus size and headways optimization model considering elastic demand. Journal of Transportation Engineering [online]. 2014, 140(4), 04013021. ISSN 2473-2893. Available from: https://doi.org/10.1061/(asce)te.1943-5436.0000641

[12] ALIZADEH FOROUTAN, R., REZAEIAN, J., MAHDAVI, I. Green vehicle routing and scheduling problem with heterogeneous fleet including reverse logistics in the form of collecting returned goods. Applied Soft Computing [online]. 2020, 94, 106462. ISSN 1568-4946. Available from: https://doi.org/10.1016/j.asoc.2020.106462

[13] GKIOTSALITIS, K., WU, Z., CATS, O. A cost-minimization model for bus fleet allocation featuring the tactical generation of short-turning and interlining options. Transportation Research Part C: Emerging Technologies [online]. 2019, 98, p. 14-36. ISSN 0968-090X. Available from: https://doi.org/10.1016/j.trc.2018.11.007

[14] NAUMOV, V. Synchronisation of timetables for public bus lines using genetic algorithms and computer simulations. Lecture Notes in Networks and Systems [online]. 2018, 36, p. 44-53. ISSN 2367-3389. Available from: https://doi.org/10.1007/978-3-319-74454-4_4

[15] TARAN, I., LITVIN, V. Determination of rational parameters for urban bus route with combined operating mode. Transport Problems [online]. 2018, 13(4), p. 157-171. ISSN 2300-861X. Available from: https://doi.org/10.20858/ tp.2018.13.4.14

[16] SANCHEZ-MARTINEZ, G., KOUTSOPOULOS, H., WILSON, N. Optimal allocation of vehicles to bus routes using automatically collected data and simulation modelling. Research in Transportation Economics [online]. 2016, 59, p. 268-276. ISSN 0739-8859. Available from: https://doi.org/10.1016/j.retrec.2016.06.003

[17] TELLEZ, O., VERCRAENE, S., LEHUEDE, F., PETON, O., MONTEIRO, T. The fleet size and mix dial-a-ride problem with reconfigurable vehicle capacity. Transportation Research Part C: Emerging Technologies [online]. 2018, 91, p. 99-123. ISSN 0968-090X. Available from: https://doi.org/10.1016/j.trc.2018.03.020

[18] TURAN, H., ELSAWAH, S., RYAN, M. A long-term fleet renewal problem under uncertainty: A simulation-based optimization approach. Expert Systems with Applications [online]. 2020, 145, 113158. ISSN 0957-4174. Available from: https://doi.org/10.1016/j.eswa.2019.113158

[19] KOC, C., BEKTAS, T., JABALI, O., LAPORTE, G. The fleet size and mix location-routing problem with time windows: Formulations and a heuristic algorithm. European Journal of Operational Research [online]. 2016, 248(1), p. 33-51. ISSN 0377-2217. Available from: https://doi.org/10.1016/j.ejor.2015.06.082

[20] SAEED OSMAN, M. Uncertainty modeling for bus selection and allocation in a private transportation system. Transportation Planning and Technology [online]. 2019, 42(7), p. 714-728. ISSN 1029-0354. Available from: https://doi.org/10.1080/03081060.2019.1650435 
[21] LIANG, S., MA, S., HE, S. Multi objective optimal formulations for bus fleet size of public transit under headwaybased holding control. Journal of Advanced Transportation [online]. 2019, 2019, 2452348. ISSN 2042-3195. Available from: https://doi.org/10.1155/2019/2452348

[22] OWEN, G. Game Theory, 4. ed. Bingley: Emerald Group Publishing, 2013. ISBN 978-1781905074.

[23] NAUMOV, V., ZHAMANBAYEV, B., AGABEKOVA, D., ZHANBIROV, Z., TARAN, I. Fuzzy-logic approach to estimate the passengers' preference when choosing a bus line within the public transport system. Communications - Scientific Letters of the University of Zilina [online]. 2021, 23(3), p. A150-A157. ISSN 2585-7878, eISSN 2585-7878. Available from: https://doi.org/10.26552/com.C.2021.3.A150-A157

[24] NAUMOV, V., SAMCHUK, G. Class library for simulations of passenger transfer nodes as elements of the public transport system. Procedia Engineering [online]. 2017, 187, p. 77-81. Available from: https://doi.org/10.1016/j. proeng.2017.04.352 